\title{
Herpes simplex virus-based nerve targeting gene therapy in pain management
}

\author{
This article was published in the following Dove Press journal: \\ Journal of Pain Research \\ 20 January 2014 \\ Number of times this article has been viewed
}

\author{
James R Goss \\ David Krisky \\ James Wechuck \\ Darren Wolfe \\ PeriphaGen Inc, Pittsburgh, PA, USA
}

Correspondence: James R Goss PeriphaGen Inc, 2100 Wharton Street, Suite 70I, Pittsburgh,

PA 15203, USA

Tel + I 4 I 4880348 ext 103

Fax + | 4I24880349

Email james.goss@periphagen.com

\begin{abstract}
Chronic pain represents a major medical burden not only in terms of suffering but also in terms of economic costs. Traditional medical approaches have so far proven insufficient in treating chronic pain and new approaches are necessary. Gene therapy with herpes simplex virus (HSV)-based vectors offers the ability to directly target specific regions of the neuraxis involved in pain transmission including the primary afferent nociceptor. This opens up new targets to interact with that are either not available to traditional systemic drugs or cannot be adequately acted upon without substantial adverse off-target effects. Having access to the entire neuron, which HSV-based vector gene therapy enables, expands treatment options beyond merely treating symptoms and allows for altering the basic biology of the nerve. In this paper, we discuss several HSV-based gene therapy vectors that our group and others have used to target specific neuronal functions involved in the processing of nociception in order to develop new therapies for the treatment of chronic pain.
\end{abstract}

Keywords: pain, gene therapy, herpes simplex virus, opioids, voltage-gated sodium channels, inhibitory neurotransmitters

\section{Introduction}

Pain as an unpleasant experience to a noxious stimulus is a useful evolutionary adaptation. It is usually associated with two phenomena, ie, hyperalgesia, or increased pain sensitivity, and allodynia, or a painful response to a normally innocuous stimulus. Typically these two phenomena fade as the initiating noxious stimulus is removed and/ or the resultant tissue injury resolves. In some instances this pain persists in the absence of stimuli or tissue injury. At this point, the pain is no longer adaptive and becomes a disease itself; this is generally termed "chronic pain". Chronic pain can result from a myriad of causes, including arthritis and rheumatism, back or neck problems, frequent headaches, painful neuropathies, trigeminal neuralgia or mandibular joint disorder, pelvic and abdominal disorders, and fibromyalgia or complex regional pain syndrome. The current estimate of the number of adult Americans suffering from chronic pain is approximately 100 million. ${ }^{1,2}$ One recent Internet-based survey showed that $30.7 \%$ of respondents reported some form of chronic pain lasting 6 months or longer. ${ }^{3}$ Of these subjects, $32 \%$ reported their chronic pain as severe ( $\geq 7$ on a scale from 0 to 10 ). The financial cost of chronic pain in the US is over $\$ 600$ billion, of which half are direct medical expenditures and half lost productivity. ${ }^{1}$ Clearly, chronic pain represents a major cause of morbidity, significantly impairing individual quality of life and imposing a substantial burden on society. 


\section{Nociceptive versus neuropathic pain}

Pain is often described as being either nociceptive or neuropathic. Nociceptive pain results from activation of neuronal pain pathways from damage to non-neuronal tissues, such as muscles, joints, viscera, and skin. This type of damage excites local primary afferent nociceptors (PANs) that are activated by specific receptors or ion channels sensitive to heat, mechanical stimuli, protons, or cold. ${ }^{4}$ The central projections of PANs, which have their cell bodies in the dorsal root ganglia, synapse with nociceptive-specific and wide dynamic range projection neurons in the dorsal horn of the spinal cord, which, in turn, project centrally to transmit the affective and discriminatory components of pain. These components of pain processing are further influenced by excitatory and inhibitory interneurons within the dorsal horn. ${ }^{5}$ Neuropathic pain results from a lesion, disease, or dysfunction of the nociceptive pathway itself, either in the presence or absence of other tissue damage, although not all lesions of this pathway result in pain.,

Injury to tissues leading to nociceptive pain cause the release of several inflammatory molecules capable of stimulating PANs, including hydrogen and potassium ions, serotonin, substance P, glutamate, histamine, bradykinins/ tachykinins, prostaglandins, and leukotrienes ${ }^{8}{ }^{89}$ In a process known as peripheral sensitization, these compounds alter the response characteristics of the primary nociceptors, made up of unmyelinated C-fibers and thinly myelinated $\mathrm{A} \delta$ fibers, by activating second messenger systems such as protein kinase $\mathrm{A}$ and protein kinase $\mathrm{C}$ (PKC) in primary nociceptors, causing increased sensitivity of endogenous receptors and altered sodium channel distribution, resulting in a lowered activation threshold and increased sensitivity to pain. ${ }^{4,10}$ This may also have the added effect of activating previously silent nociceptors. The end result of all these changes is an increase in nociceptive input into the spinal cord.

Prolonged nociceptive input results in similar changes in the spinal cord, resulting in "central sensitization". Activation of intracellular kinases within projection neurons causes phosphorylation of ion channels and receptors, resulting in immediate central sensitization. ${ }^{4}$ In addition, the same second messenger systems activate transcription factors, causing altered gene expression and long-lasting changes in the physiology of projection neurons, resulting in delayed central sensitization. Central sensitization is characterized by an increase in receptive field size, a reduction in threshold, and an increase in responsiveness in individual projection neurons which can cause nociceptive-specific neurons to behave like wide dynamic range neurons and respond to normally nonpainful stimuli, resulting in allodynia. ${ }^{4,11-13}$ The phenomenon of windup in wide dynamic range neurons is also involved in central sensitization, and is known to involve activation of the N-methyl-D-aspartate subtype glutamate receptor. ${ }^{14}$

Peripheral nerve injury can lead to neuropathic pain through mechanisms that are not completely understood. ${ }^{7}$ Injured afferent neurons develop spontaneous neural activity and ectopic discharges ${ }^{15}$ while the uninjured afferent neurons can undergo peripheral sensitization as described above. ${ }^{16}$ Changes in trophic factor support affect both injured and uninjured afferents, and can alter gene expression in dorsal root ganglia neurons, resulting in increased pain sensitivity. ${ }^{17,18}$ Central sensitization also occurs in response to nerve injury, but unlike that involved with inflammation, which is dependent on ongoing nociceptive input, the central sensitization associated with neuropathic pain can involve different sets of afferents. ${ }^{7}$ For example, low-threshold $A \beta$ fibers responsive to touch shift to a nociceptor-like phenotype or synapse on sensitized nociceptive-specific and wide dynamic range neurons, resulting in a painful sensation to a light touch stimulus (allodynia), ${ }^{19}$ and there is a change in the subtypes of voltage-gated sodium channels that are expressed in injured PANs, resulting in altered signal propagation..$^{20}$ Peripheral nerve damage is also associated with apoptosis of dorsal horn interneurons. ${ }^{21}$ These largely inhibitory neurons synapse with both the PANs and projection neurons and express gamma aminobutyric acid (GABA), glycine, and endogenous opioid peptides such as enkephalin and endomorphin in order to modulate pain signaling from the periphery. A downregulation in the receptors for these inhibitory neurotransmitters also occurs in response to nerve injury. ${ }^{21}$

In addition to the above mechanisms, substance $\mathrm{P}$ and glutamate released by the PANs and prostaglandins and nitrous oxide released by the nociceptive-specific and wide dynamic range neurons activate glia within the dorsal horn, which in turn release proinflammatory cytokines and growth factors that have hyperalgesic effects, resulting in a positive feedback mechanism of increased and prolonged pain. ${ }^{22}$

\section{Difficulty in treating chronic pain}

Chronic pain is a debilitating disease because, for many patients, currently available analgesics either do not offer adequate pain relief or produce intolerable side effects. In regards to nociceptive pain, the best treatment is repair of the injured tissue; however, for many chronic conditions, such as arthritis or cancer, this may not be possible. While nonsteroidal anti-inflammatory drugs are used to treat 
mild inflammatory pain, opioids or narcotic analgesics are an essential component of chronic nociceptive pain management. These drugs, eg, morphine, act at opioid mu, delta, and kappa receptors in the dorsal horn to inhibit nociceptive transmission. ${ }^{23}$ Unfortunately, these receptors are found throughout the neuraxis and body tissues, so the long-term use of opioid drugs is limited by adverse systemic effects, including nausea, constipation, dizziness, drowsiness, and respiratory depression, the development of tolerance, and ultimately dependence on such drugs.

The diverse mechanisms underlying neuropathic pain make it difficult to establish a unified clinical management approach because patients who present with the same symptoms may respond differently to the same medication. Generally, patients with neuropathic pain respond poorly to nonsteroidal anti-inflammatory drugs or opioids. The classes of medications that have proven most beneficial to date are anticonvulsants and antidepressants, no doubt reflecting the role that abnormal neuronal activity plays in the pathophysiology of neuropathic pain. ${ }^{24}$ While some patients respond well to these types of drugs, it is estimated that half of all patients suffering from neuropathic pain receive little, if any, pain relief from currently available drugs. ${ }^{25}$

\section{Gene therapy approaches for treating chronic pain}

The medical and economic burden of chronic pain coupled with insufficient treatment options make the development of novel approaches necessary, and gene therapy is one such approach. Gene therapy (or gene transfer) refers to the introduction and expression of DNA or RNA sequences in tissues and/or cells. It can be used to express proteins, or other gene products, that directly target the neurologic components underlying nociception, such as receptors, neurotransmitters, ion channels, second messenger systems, and biochemical mediators of inflammation. ${ }^{26,27}$ Gene therapy has several benefits compared with traditional pharmaceuticals in the treatment of chronic pain. Therapeutic genes can be delivered to specific regions and/or cells in the neuraxis, resulting in a localized concentration of the gene product. This significantly increases effectiveness while simultaneously reducing systemic adverse effects compared with traditional drugs. Small molecule drugs typically require large systemic doses to ensure adequate local concentrations of drug products, often resulting in side effects. Through targeted delivery and/or the use of specialized gene products (eg, transcription factors, dominant/negative genes, small interfering (si)RNA), a far greater number of potential therapeutic targets become available to act upon and inhibit pain signaling. Loss of efficacy due to tolerance is very unlikely to occur with gene therapy due to the relatively small amount of therapeutic protein expressed and the tendency to utilize endogenous protein products, which are not normally subject to tolerance. Gene therapy offers the possibility of long-term expression of therapeutic proteins in specific cells, an especially attractive benefit for treating chronic conditions. Lastly, there is almost no possibility for abuse or addiction because the effect remains local and does not interact with higher brain centers.

Any location along the pain pathway can be targeted by gene therapy, but the PANs and their synapse with second order neurons in the dorsal horn are ideal because they are integral in the pathophysiology of chronic pain. Three gene therapy strategies have been employed to deliver analgesic genes to the nervous system: cell-based therapies, usually transplantation of transformed cells into the subarachnoid space; ${ }^{28-30}$ use of plasmids or oligonucleotides, sometimes encapsulated in liposomes to facilitate entry into cells; $;^{31-33}$ and use of viral-based vectors. Viral vector gene therapy takes advantage of the natural ability of viruses to infect and have their genes expressed by host cells and has been the most utilized system for gene delivery into the nervous system. ${ }^{34,35}$

\section{Herpes simplex virus as a vector system for treating chronic pain}

Among the several viral-based vector systems capable of gene delivery, herpes simplex virus-1 (HSV)-based vectors are especially useful for delivery to the nervous system and PANs. HSV is a large human virus containing $152 \mathrm{~kb}$ of linear double-stranded DNA encoding at least 75 gene products. The virus particle consists of a nucleocapsid surrounded by an envelope containing glycoproteins essential for virus attachment and penetration into cells. The virus genome consists of two segments, the unique long $\left(\mathrm{U}_{\mathrm{L}}\right)$ and unique short $\left(\mathrm{U}_{\mathrm{S}}\right)$, each flanked by inverted repeats. Approximately half of the gene products are not essential for growth in cell culture. Once these nonessential genes have been deleted, 40-50 kb of foreign DNA can be accommodated within the virus.

In its natural life cycle, wild-type HSV is spread by direct contact. It infects and replicates in skin or mucous membrane and released viral particles are taken up by sensory nerve terminals. ${ }^{36}$ These particles travel via retrograde transport along axons to the neuronal perikaryon in the dorsal root ganglia, where wild-type HSV may either re-enter the lytic cycle or alternatively establish a latent state that is characterized by the persistence of viral genomes as nonreplicating intranuclear episomal elements. In the lytic life cycle, viral 
immediate early genes transactivate expression of viral early genes, the products of which principally code for proteins required for viral DNA replication. ${ }^{37}$ Replicationdefective HSV vectors can be engineered by removing one or more genes that code for immediate early gene products. These vectors can only replicate in specialized cell lines that provide the missing gene product but are still capable of infecting sensory neurons and expressing an inserted transgene product. ${ }^{38-40}$ Transgene expression is mediated by the choice of promoter. Short-term (weeks) expression is achieved using a strong promoter such as the immediate early gene promoter derived from human cytomegalovirus. HSV possesses a natural promoter system that is uniquely active during latency when all the other viral promoters are repressed. ${ }^{41}$ This latency active promoter has been used for the long-term (months) expression of transgenes in sensory neurons of the peripheral and central nervous systems. ${ }^{42,43}$

Due to the natural biology of the parent virus, HSVbased vectors injected into the dermal layer of the skin will infect the sensory nerves innervating that area. Thus, by selecting the correct dermatome for direct vector inoculation, one can specifically target the sensory neurons in which one wants to express the therapeutic product. This restricts the "therapy" to the most appropriate region of the body, both minimizing the possibility of side effects while maximizing therapeutic efficacy.

\section{Strategies for using HSV vectors to treat pain}

Because HSV-based vectors can easily be delivered to sensory neurons, several potential therapeutic targets are available that could interfere with the processing of noxious stimuli from the periphery to the central nervous system (Figure 1). One such target is the synapse between the PAN and projection neuron within the dorsal horn. Projections from the brainstem can alter pain perception through interaction with interneurons located in the dorsal horn. ${ }^{44}$ These interneurons use inhibitory neurotransmitters to modulate the activity of both primary nociceptors and projection neurons, and as discussed above, pathologic changes in these neurons have been observed with chronic pain. Our group and others have used replication-defective HSV-based vectors to overexpress and/or increase the activity of these inhibitory neurotransmitters in PANs, and thus increase the overall inhibitory tone at this synapse.

The first of these transmitters to be expressed was the endogenous opioid peptide enkephalin (ENK), which is the natural ligand for the delta opioid receptor. ${ }^{45} \mathrm{HSV}$ vectormediated transfer of the ENK gene to lumbar dorsal root ganglia of rodents via footpad inoculation has been demonstrated to reduce $\mathrm{C}$-fiber-evoked pain behaviors in response to acute inflammatory stimuli, such as injection of capsaicin ${ }^{46}$ or formalin, ${ }^{47}$ and decrease hyperalgesia associated with chronic

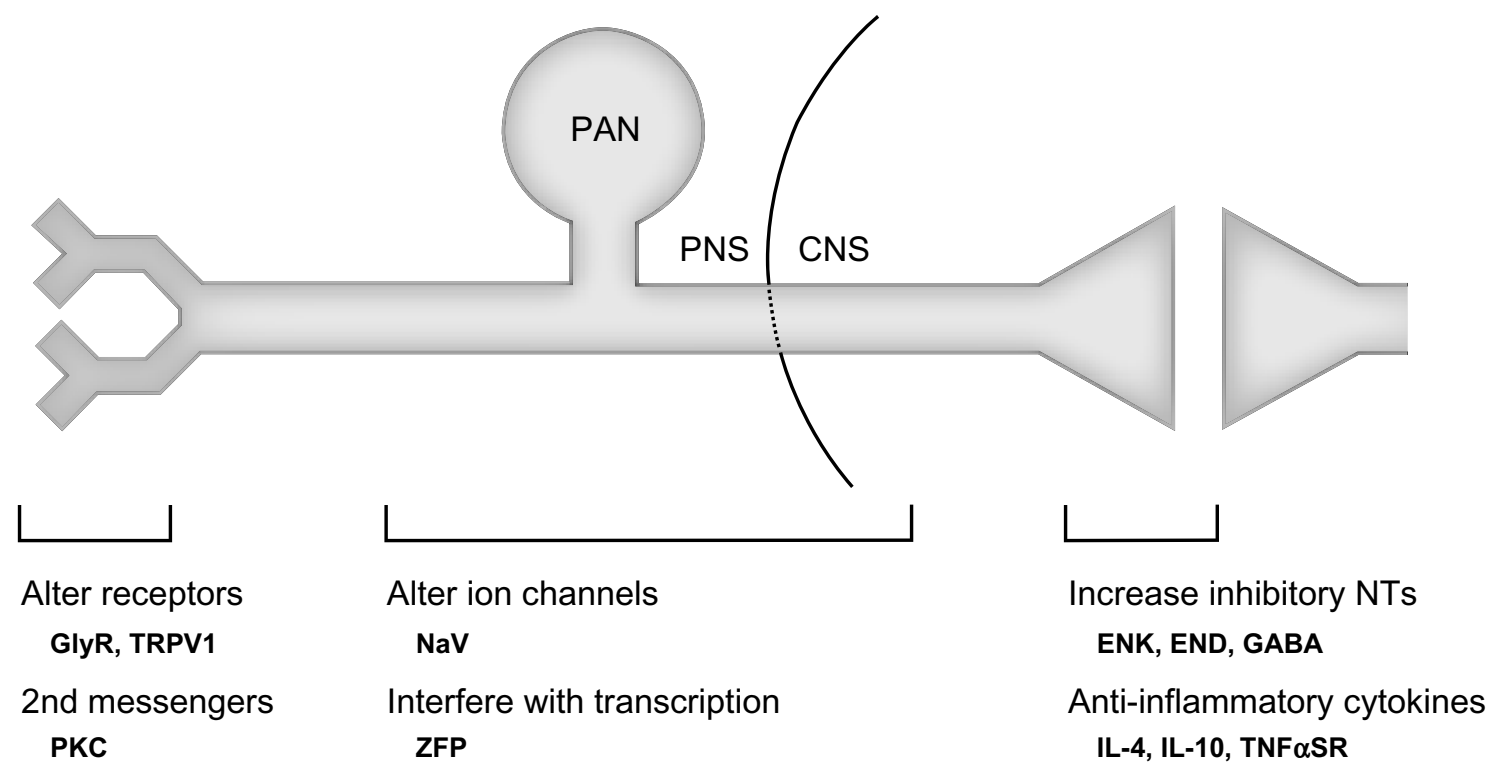

Figure I Potential therapeutic target areas to treat pain that are accessible via HSV-based gene transfer. The illustration represents a primary afferent nociceptor with its receptive field in the periphery and its synapse with a projection neuron in the dorsal horn of the spinal cord. HSV-based gene transfer can be used to interfere with pain processing at many locations along this route. Specific targets (shown in bold) that have been demonstrated to decrease nociceptive responses in animal models of pain are shown for each location.

Abbreviations: GlyR, glycine receptor; TRPVI, transient receptor potential vanilloid type I; PKC, protein kinase C; NaV, voltage-gated sodium channel; ZFP, zinc finger protein transcription factor; ENK, enkephalin; END, endomorphin; GABA, gamma aminobutyric acid; IL-4, interleukin-4; IL-I0, interleukin-I0; TNF $\alpha$ SR, tumor necrosis factor alpha soluble receptor; HSV, herpes simplex virus; PAN, primary afferent nociceptor; PNS, peripheral nervous system; CNS, central nervous system; NTs, neurotransmitters. 
inflammation ${ }^{48,49}$ and bone cancer. ${ }^{50}$ Similarly, footpad inoculation has been shown to reduce nociceptive behavior in rodent models of chronic neuropathic pain, including spinal nerve ligation ${ }^{51}$ and painful diabetic neuropathy, ${ }^{52}$ while application to the rat vibrissal pad has reduced neuropathic pain associated with trigeminal neuralgia. ${ }^{53}$ Others have since shown that ENK-expressing HSV vectors directly applied to the bladder or pancreas produce analgesia in visceral pain models of cystitis and pancreatitis ${ }^{54-56}$ and extended findings to primates. ${ }^{57} \mathrm{All}$ of these studies led to the first human gene therapy trial for the treatment of pain. In a ten-person, open-label, dose-escalation trial, NP2, an ENK-expressing HSV vector, demonstrated a positive safety profile with no serious adverse events in patients with severe focal pain due to cancer. Analysis of daily numeric pain scores over the course of the study ( 28 days) suggested a dose-related analgesic response to the drug. ${ }^{58}$

Two other inhibitory neurotransmitters that play a role in nociceptive transmission at the dorsal horn synapse have been utilized as HSV vector transgenes, ie, GABA and endomorphin. GABA is the dominant inhibitory neurotransmitter in the spinal cord and exerts tonic inhibitory control over nociceptive transmission primarily via $\mathrm{GABA}_{\mathrm{A}}$ and $\mathrm{GABA}_{\mathrm{B}}$ receptors found presynaptically and postsynaptically on dorsal horn neurons. The evidence suggests that prolonged nociceptor excitation reduces the GABA-mediated tonic inhibition within the dorsal horn by reducing presynaptic GABA production and/or release. ${ }^{59}$ GABA synthesis in PANs can be increased using HSV vectors expressing the rate-limiting enzyme in the biosynthesis of GABA from glutamate, ie, glutamic acid decarboxylase. HSV vectors expressing glutamic acid decarboxylase are more effective in reducing neuropathic pain in rodent models of spinal nerve ligation, spinal cord injury, or painful diabetic neuropathy ${ }^{60-63}$ compared with ENK-expressing vectors, but less effective in reducing pain-related behaviors in animal models of inflammatory pain (formalin test, bone cancer; JRG, personal observation). Endomorphin is a natural ligand of the mu opioid receptor, which is the major site of action for narcotic drugs such as morphine. While no natural endomorphin gene has been identified, our group engineered an HSV vector containing a synthetic endomorphin gene construct based on the known amino acid sequence. This vector demonstrated antinociceptive properties in the spinal nerve ligation model of neuropathic pain ${ }^{64}$ and the complete Freund's adjuvant model of inflammatory pain. ${ }^{65}$ Interestingly, this vector demonstrated an analgesic effect in rats with opiate tolerance induced by daily treatments with morphine, suggesting that there is no cross-tolerance between morphine and vector-mediated endomorphin.

Aside from increasing inhibitory tone at the dorsal horn synapse, HSV vectors can be used to release antiinflammatory molecules at this site to decrease the effects of glia-mediated neuroimmune activation that occur in response to chronic pain. Anti-inflammatory cytokines such as interleukin-4 (IL-4), IL-10, and IL-13 have been shown to have analgesic properties in several different animal models of acute and chronic pain. ${ }^{66-70}$ Along the lines of those experiments, HSV-mediated expression of IL-4 or tumor necrosis factor alpha soluble receptor in lumbar dorsal root ganglia neurons following footpad inoculation significantly decreases pain-related behavior in the spinal nerve ligation model of neuropathic pain ${ }^{71,72}$ and an HSV vector expressing IL-10 decreases spontaneous paw flinches in the formalin model of acute inflammatory pain. ${ }^{73}$ Other studies have used direct intrathecal administration to the lumbar spinal cord of adenovirus or adenoassociated virusbased vectors expressing IL-10 to reduce neuropathic pain in animals. ${ }^{74,75}$

Another set of potential therapeutic targets accessible to HSV vectors are the receptors that transduce noxious stimuli to electrical potentials within the PANs. These targets are only now being examined, but could provide a more fine-tuned approach to pain control, ie, decrease pain from a specific stimuli such as heat. For example, the transient receptor potential vanilloid type 1 (TRPV1) receptor is an ion channel activated by high temperature and involved in painful heat sensation. Transduction of rodent dorsal root ganglia by footpad inoculation with an HSV vector expressing a mutant TRPV1 gene that does not form the channel results in a significantly attenuated thermal response, ${ }^{76}$ but does not affect an animal's response to cold temperature (JRG, personal observation). A similar effect has been achieved by using an HSV vector that expresses a dominant negative protein kinase $\mathrm{C}$ epsilon. TRPV1 activity is regulated by phosphorylation via protein kinase $C$ epsilon and introduction of a dominant negative form of the enzyme alters the response of rats to capsaicin. ${ }^{77}$ Another approach involves the insertion of novel receptors into sensory neurons. Our group has used an HSV vector expressing the glycine receptor as a "regulatable target" in this regard. Glycine is an inhibitory neurotransmitter used throughout the nervous system but primary sensory neurons do not express glycine receptors. Inoculation into the footpad in rats with a glycine receptor vector resulted in a reduction in inflammatory pain-related behavior following application of glycine to the paw. ${ }^{78}$ This method could be 
refined by using vectors that express channels or receptors that respond to other ligands or drugs.

Other attractive therapeutic targets within the PANs are the ion channels responsible for propagating the transduced stimuli at the periphery to the terminals located in the dorsal horn. Voltage-gated sodium channels are especially interesting candidates because these proteins lie at points of convergence and are necessary for normal nociceptive processing. It is known that the voltage-gated sodium channels NaV1.7, NaV1.8, and NaV1.9 play roles in nociception, and modifying their function has become a natural focus in recent studies. ${ }^{79}$ The sodium channel subunit NaV1.7 plays a significant role in action spike initiation, and natural gainof-function and loss-of-function mutations are associated with clinical pain syndromes of paroxysmal extreme pain disorder and congenital insensitivity to pain, respectively. ${ }^{80,81}$ Further, the reductions in diabetic neuropathy pain-related behavior associated with the HSV-glutamic acid decarboxylase and HSV-ENK gene therapy studies discussed above appear to be partly attributable to decreased expression of $\mathrm{NaV} 1.7$ in dorsal root ganglia neurons. ${ }^{52,63}$ Not surprisingly, knockdown of NaV1.7 via HSV-mediated expression of a microRNA or an antisense oligodeoxynucleotide has been shown to reduce hyperalgesia in models of painful diabetic neuropathy and inflammation. ${ }^{82,83} \mathrm{NaV} 1.8$ and NaV1.9 are tetrodotoxin-resistant voltage-gated sodium channels expressed in nociceptors. NaV1.8-null mice have decreased behavioral responses to thermal and mechanical stimuli, indicating a role for nociception for this particular channel, ${ }^{84}$ but a clearer role for NaV1.9 has been more difficult to discern. ${ }^{79}$ In pilot data collected by our group, we demonstrated that HSV vectors expressing zinc finger protein transcription repressors targeted against $\mathrm{NaV} 1.8$ can reduce transcription of this protein in vitro and reduce nociceptive behaviors in a rat model of neuropathic pain. ${ }^{85}$

\section{Future outlook}

As chronic pain continues to be a major health issue that is underserved with currently available drugs, new treatment approaches will be developed and tested. Gene therapy with HSV-based vectors is one such approach and offers the ability to directly act upon the specific neurons and area of the nervous system that are involved in the processing of nociception. However, there remain dosing, safety, and cost issues that will need to be addressed before gene therapy becomes a fully accepted treatment option for the management of pain. Treatment for chronic pain will depend on long-term expression of the therapeutic gene product, which could be achieved by using a long-term promoter but will more likely involve repeat dosing of the vector product. Our group has demonstrated that readministration of HSV-based vectors is both safe and effective in re-establishing analgesia in rodent models of nociceptive and neuropathic pain. ${ }^{47,51,60,71}$ Long-term expression of a transgene carries its own risks. Once applied, many viral vector-based gene transfer vectors, HSV included, could persist in cells for the life of the patient. This could be quite problematic if the patient had an adverse reaction to the expressed transgene. For this reason, it may be preferential to use short-duration promoters in vector constructs. Alternatively, a regulatable system capable of turning gene expression "on" and "off" could be used. ${ }^{86}$ While such a system has been used in HSV vectors to control the expression of erythropoietin in the treatment of diabetic neuropathy, it has not yet been utilized to treat pain. ${ }^{87}$ A practical concern is one of cost. The process and subsequent costs associated with growing, isolating, and purifying gene transfer vectors are substantially different from those associated with traditional small molecule therapeutics. The ultimate cost per treatment can only be known once indications and target populations have been identified. We believe that the potential increased efficacy of this approach or the ability to treat otherwise intractable patient populations will drive the acceptance of gene therapy to treat pain, and enhanced manufacturing processes and market forces will stabilize the costs to a point acceptable to both patients and payers. Drug products based on HSV vectors that utilize a short-duration promoter such as the human cytomegalovirus promoter would be expected to be readministered every 2-3 months. The choice of transgene would depend on the indication and preclinical animal model studies; as stated above, some transgenes are more efficacious than others in specific pain models.

Several targets, especially within the PAN, have been examined to date, resulting in a substantial amount of preclinical data supporting an HSV-based gene therapy approach in pain management. HSV vectors enable retrograde transduction of PANs via intradermal application but direct injection to nervous system structures is also possible. Zou et al demonstrated that direct injection of an ENK-expressing HSV amplicon vector into the rat ventral periaqueductal gray region resulted in an increased pain threshold in chronic constriction injury-induced neuropathic pain. ${ }^{8}$ Intradermal inoculation of HSV vectors may be sufficient for well localized focal pain, but application to higher nervous system structures such as the periaqueductal gray may be needed to treat more global pain disorders, such as complex regional pain syndrome. 
Future studies will be needed to address this issue. To date, preclinical animal studies have focused on targets aiming to treat pain symptoms. Increasing the inhibitory tone at the primary synapse using ENK, endomorphin, or periaqueductal gray-expressing vectors are intended to interfere with pain transmission, but do not alter the underlying pathology. The use of anti-inflammatory vectors may affect central sensitization, but do not necessarily treat the causative problem. As our understanding of the pathophysiology of chronic pain increases, new targets will reveal themselves and vectors designed to treat the cause and not just the symptoms will be developed, tested, and moved into the clinic.

\section{Disclosure}

The authors report no conflicts of interest in this work.

\section{References}

1. Institute of Medicine, editor. Relieving Pain in America: A Blueprint for Transforming Prevention, Care, Education, and Research. Washington, DC: The National Academies Press: 2001.

2. Tsang A, Von Korff M, Lee S, et al. Common chronic pain conditions in developed and developing countries: gender and age differences and comorbidity with depression-anxiety disorders. J Pain. 2008;9(10): 883-891.

3. Johannes CB, Le TK, Zhou X, Johnston JA, Dworkin RH. The prevalence of chronic pain in United States adults: results of an Internet-based survey. J Pain. 2010;11(11):1230-1239.

4. Scholz J, Woolf CJ. Can we conquer pain? Nat Neurosci. 2002;Suppl 5: 1062-1067.

5. Todd AJ. Neuronal circuitry for pain processing in the dorsal horn. Nat Rev Neurosci. 2010;11(12):823-836.

6. Boivie J, Leijon G, Johansson I. Central post-stroke pain - a study of the mechanisms through analyses of the sensory abnormalities. Pain. 1989;37(2):173-185.

7. Campbell JN, Meyer RA. Mechanisms of neuropathic pain. Neuron. 2006;52(1):77-92.

8. Mizumura K. Peripheral mechanism of hyperalgesia - sensitization of nociceptors. Nagoya J Med Sci. 1997;60(3-4):69-87.

9. Curatolo M, Arendt-Nielsen L, Petersen-Felix S. Central hypersensitivity in chronic pain: mechanisms and clinical implications. Phys Med Rehabil Clin N Am. 2006;17(2):287-302.

10. Zimmermann M. Pathobiology of neuropathic pain. Eur J Pharmacol. 2001;429(1-3):23-37.

11. McMahon SB, Wall PD. Receptive fields of rat lamina 1 projection cells move to incorporate a nearby region of injury. Pain. 1984;19(3): 235-247.

12. Millan MJ. The induction of pain: an integrative review. Prog Neurobiol. 1999;57(1):1-164.

13. Woolf CJ. Windup and central sensitization are not equivalent. Pain. 1996;66(2-3):105-108.

14. Dickenson AH, Sullivan AF. Evidence for a role of the NMDA receptor in the frequency dependent potentiation of deep rat dorsal horn nociceptive neurones following $\mathrm{C}$ fibre stimulation. Neuropharmacology. 1987;26(8):1235-1238.

15. Devor M. Response of nerves to injury in relation to neuropathic pain. In: McMahon SB, Koltzenburg M, editors. Wall and Melzack's Textbook of Pain. London, UK: Elsevier; 2006.

16. Shim B, Kim DW, Kim BH, Nam TS, Leem JW, Chung JM. Mechanical and heat sensitization of cutaneous nociceptors in rats with experimental peripheral neuropathy. Neuroscience. 2005;132(1):193-201.
17. Griffin JW. The roles of growth factors in painful length-dependent axonal neuropathies. In: Campbell JN, Basbaum AI, Dray A, et al, editors. Emerging Strategies for the Treatment of Neuropathic Pain. Seattle, WA: IASP Press; 2006.

18. Boucher TJ, McMahon SB. Neurotrophic factors and neuropathic pain. Curr Opin Pharmacol. 2001;1(1):66-72.

19. Neumann S, Doubell TP, Leslie T, Woolf CJ. Inflammatory pain hypersensitivity mediated by phenotypic switch in myelinated primary sensory neurons. Nature. 1996;384(6607):360-364.

20. Gold MS, Weinreich D, Kim CS, et al. Redistribution of $\mathrm{Na}(\mathrm{V}) 1.8$ in uninjured axons enables neuropathic pain. $J$ Neurosci. 2003;23(1): $158-166$.

21. Kohno T, Ji RR, Ito N, et al. Peripheral axonal injury results in reduced $\mathrm{mu}$ opioid receptor pre- and post-synaptic action in the spinal cord. Pain. 2005;117(1-2):77-87.

22. Watkins LR, Milligan ED, Maier SF. Glial activation: a driving force for pathological pain. Trends Neurosci. 2001;24(8):450-455.

23. Pasternak GW. Pharmacological mechanisms of opioid analgesics. Clin Neuropharmacol. 1993;16(1):1-18.

24. Irving GA. Contemporary assessment and management of neuropathic pain. Neurology. 2005;64(12 Suppl 3):S21-S27.

25. Hansson P, Lacerenza M, Marchettini P. Aspects of clinical and experimental neuropathic pain: the clinical perspective. In: Hansson PT, Fields HL, Hill RG, Marchettini P, editors. Neuropathic Pain: Pathophysiology and Treatment. Seattle, WA: IASP Press; 2001.

26. Wu CL, Garry MG, Zollo RA, Yang J. Gene therapy for the management of pain. Part I: methods and strategies. Anesthesiology. 2001;94(6):1119-1132.

27. Wu CL, Garry MG, Zollo RA, Yang J. Gene therapy for the management of pain. Part II: molecular targets. Anesthesiology. 2001;95(1):216-240.

28. Eaton MJ, Plunkett JA, Martinez MA, et al. Transplants of neuronal cells bioengineered to synthesize GABA alleviate chronic neuropathic pain. Cell Transplant. 1999;8(1):87-101.

29. Ishii K, Isono M, Inoue R, Hori S. Attempted gene therapy for intractable pain: dexamethasone-mediated exogenous control of beta-endorphin secretion in genetically modified cells and intrathecal transplantation. Exp Neurol. 2000;166(1):90-98.

30. Duplan H, Li RY, Vue C, et al. Grafts of immortalized chromaffin cells bio-engineered to improve met-enkephalin release also reduce formalinevoked c-fos expression in rat spinal cord. Neurosci Lett. 2004;370(1): $1-6$.

31. Luo D, Saltzman WM. Synthetic DNA delivery systems. Nat Biotechnol. 2000;18(1):33-37.

32. Yao MZ, Gu JF, Wang JH, et al. Interleukin-2 gene therapy of chronic neuropathic pain. Neuroscience. 2002;112(2):409-416.

33. Wu CM, Lin MW, Cheng JT, et al. Regulated, electroporation-mediated delivery of pro-opiomelanocortin gene suppresses chronic constriction injury-induced neuropathic pain in rats. Gene Ther. 2004;11(11): 933-940.

34. Kay MA, Glorioso JC, Naldini L. Viral vectors for gene therapy: the art of turning infectious agents into vehicles of therapeutics. Nat Med. 2001;7(1):33-40.

35. Davidson BL, Breakefield XO. Viral vectors for gene delivery to the nervous system. Nat Rev Neurosci. 2003;4(5):353-364.

36. Jacobs A, Breakefield XO, Fraefel C. HSV-1-based vectors for gene therapy of neurological diseases and brain tumors: part I. HSV-1structure, replication and pathogenesis. Neoplasia. 1999;1(5):387-401.

37. Honess RW, Roizman B. Regulation of herpesvirus macromolecular synthesis. I. Cascade regulation of the synthesis of three groups of viral proteins. J Virol. 1974;14(1):8-19.

38. DeLuca NA, McCarthy AM, Schaffer PA. Isolation and characterization of deletion mutants of herpes simplex virus type 1 in the gene encoding immediate-early regulatory protein ICP4. J Virol. 1985;56(2): 558-570.

39. Goins WF, Marconi P, Krisky D, et al. Construction of replicationdefective herpes simplex virus vectors. Curr Protoc Hum Genet. 2002; Chapter 12:Unit 12.11. 
40. Krisky DM, Marconi PC, Oligino T, Rouse RJ, Fink DJ, Glorioso JC. Rapid method for construction of recombinant HSV gene transfer vectors. Gene Ther. 1997;4(10):1120-1125.

41. Goins WF, Sternberg LR, Croen KD, et al. A novel latency-active promoter is contained within the herpes simplex virus type $1 \mathrm{U}_{\mathrm{L}}$ flanking repeats. J Virol. 1994;68(4):2239-2252.

42. Puskovic V, Wolfe D, Goss J, et al. Prolonged biologically active transgene expression driven by HSV LAP2 in brain in vivo. Mol Ther. 2004;10(1):67-75.

43. Chattopadhyay M, Wolfe D, Mata M, Huang S, Glorioso JC, Fink DJ. Long-term neuroprotection achieved with latency-associated promoterdriven herpes simplex virus gene transfer to the peripheral nervous system. Mol Ther. 2005;12(2):307-313.

44. Basbaum AI, Fields HL. Endogenous pain control systems: brainstem spinal pathways and endorphin circuitry. Annu Rev Neurosci. 1984;7: 309-338.

45. Antunes Bras JM, Epstein AL, Bourgoin S, Hamon M, Cesselin F, Pohl M. Herpes simplex virus 1-mediated transfer of preproenkephalin A in rat dorsal root ganglia. J Neurochem. 1998;70(3):1299-1303.

46. Wilson SP, Yeomans DC, Bender MA, Lu Y, Goins WF, Glorioso JC. Antihyperalgesic effects of infection with a preproenkephalin-encoding herpes virus. Proc Natl Acad Sci U S A. 1999;96(6):3211-3216.

47. Goss JR, Mata M, Goins WF, Wu HH, Glorioso JC, Fink DJ. Antinociceptive effect of a genomic herpes simplex virus-based vector expressing human proenkephalin in rat dorsal root ganglion. Gene Ther. 2001;8(7):551-556.

48. Braz J, Beaufour C, Coutaux A, et al. Therapeutic efficacy in experimental polyarthritis of viral-driven enkephalin overproduction in sensory neurons. J Neurosci. 2001;21(20): 7881-7888.

49. Yeomans DC, Jones T, Laurito CE, Lu Y, Wilson SP. Reversal of ongoing thermal hyperalgesia in mice by a recombinant herpesvirus that encodes human preproenkephalin. Mol Ther. 2004;9(1): $24-29$.

50. Goss JR, Harley CF, Mata M, et al. Herpes vector-mediated expression of proenkephalin reduces bone cancer pain. Ann Neurol. 2002;52(5): 662-665.

51. Hao S, Mata M, Goins W, Glorioso JC, Fink DJ. Transgene-mediated enkephalin release enhances the effect of morphine and evades tolerance to produce a sustained antiallodynic effect in neuropathic pain. Pain. 2003;102(1-2):135-142.

52. Chattopadhyay M, Mata M, Fink DJ. Continuous delta-opioid receptor activation reduces neuronal voltage-gated sodium channel ( $\mathrm{NaV1.7)}$ levels through activation of protein kinase $\mathrm{C}$ in painful diabetic neuropathy. J Neurosci. 2008;28(26):6652-6658.

53. Meunier A, Latrémolière A, Mauborgne A, et al. Attenuation of pain-related behavior in a rat model of trigeminal neuropathic pain by viral-driven enkephalin overproduction in trigeminal ganglion neurons. Mol Ther. 2005;11(4):608-616.

54. Yokoyama H, Sasaki K, Franks ME, et al. Gene therapy for bladder overactivity and nociception with herpes simplex virus vectors expressing preproenkephalin. Hum Gene Ther. 2009;20(1):63-71.

55. Lu Y, McNearney TA, Lin W, Wilson SP, Yeomans DC, Westlund KN. Treatment of inflamed pancreas with enkephalin encoding HSV-1 recombinant vector reduces inflammatory damage and behavioral sequelae. Mol Ther. 2007;15(10):1812-1819.

56. Yang H, McNearney TA, Chu R, et al. Enkephalin-encoding herpes simplex virus-1 decreases inflammation and hotplate sensitivity in a chronic pancreatitis model. Mol Pain. 2008;4:8.

57. Yeomans DC, Lu Y, Laurito CE, et al. Recombinant herpes vectormediated analgesia in a primate model of hyperalgesia. Mol Ther. 2006;13(3):589-597.

58. Fink DJ, Wechuck J, Mata M, et al. Gene therapy for pain: results of a phase I clinical trial. Ann Neurol. 2011;70(2):207-212.

59. Zhou HY, Zhang HM, Chen SR, Pan HL. Increased nociceptive input rapidly modulates spinal GABAergic transmission through endogenously released glutamate. $J$ Neurophysiol. 2007;97(1):871-882.
60. Hao S, Mata M, Wolfe D, Huang S, Glorioso JC, Fink DJ. Gene transfer of glutamic acid decarboxylase reduces neuropathic pain. Ann Neurol. 2005;57(6):914-918.

61. Miyazato M, Sugaya K, Saito S, et al. Suppression of detrusor-sphincter dyssynergia by herpes simplex virus vector mediated gene delivery of glutamic acid decarboxylase in spinal cord injured rats. $J$ Urol. 2010;184(3):1204-1210.

62. Liu J, Wolfe D, Hao S, et al. Peripherally delivered glutamic acid decarboxylase gene therapy for spinal cord injury pain. Mol Ther. 2004;10(1):57-66.

63. Chattopadhyay M, Mata M, Fink DJ. Vector-mediated release of GABA attenuates pain-related behaviors and reduces $\mathrm{Na}(\mathrm{V}) 1.7$ in DRG neurons. Eur J Pain. 2011;15(9):913-920.

64. Wolfe D, Hao S, Hu J, et al. Engineering an endomorphin-2 gene for use in neuropathic pain therapy. Pain. 2007;133(1-3):29-38.

65. Hao S, Wolfe D, Glorioso JC, Mata M, Fink DJ. Effects of transgene-mediated endomorphin-2 in inflammatory pain. Eur J Pain. 2009;13(4):380-386.

66. Cunha FQ, Poole S, Lorenzetti BB, Veiga FH, Ferreira SH. Cytokinemediated inflammatory hyperalgesia limited by interleukin-4. $\mathrm{Br} J$ Pharmacol. 1999;126(1):45-50.

67. Lorenzetti BB, Poole S, Veiga FH, Cunha FQ, Ferreira SH. Cytokinemediated inflammatory hyperalgesia limited by interleukin- 13 . Eur Cytokine Netw. 2001;12(2):260-267.

68. Poole S, Cunha FQ, Selkirk S, Lorenzetti BB, Ferreira SH. Cytokinemediated inflammatory hyperalgesia limited by interleukin-10. $\mathrm{Br} J$ Pharmacol. 1995;115(4):684-688.

69. Vale ML, Marques JB, Moreira CA, et al. Antinociceptive effects of interleukin-4, -10 , and -13 on the writhing response in mice and zymosan-induced knee joint incapacitation in rats. $J$ Pharmacol Exp Ther. 2003;304(1):102-108.

70. Wagner R, Janjigian M, Myers RR. Anti-inflammatory interleukin-10 therapy in CCI neuropathy decreases thermal hyperalgesia, macrophage recruitment, and endoneurial TNF-alpha expression. Pain. 1998;74(1): $35-42$.

71. Hao S, Mata M, Glorioso JC, Fink DJ. HSV-mediated expression of interleukin-4 in dorsal root ganglion neurons reduces neuropathic pain. Mol Pain. 2006;2:6.

72. Hao S, Mata M, Glorioso JC, Fink DJ. Gene transfer to interfere with TNFalpha signaling in neuropathic pain. Gene Ther. 2007;14(13): 1010-1016.

73. Zhou Z, Peng X, Hao S, Fink DJ, Mata M. HSV-mediated transfer of interleukin-10 reduces inflammatory pain through modulation of membrane tumor necrosis factor alpha in spinal cord microglia. Gene Ther. 2008;15(3):183-190.

74. Milligan ED, Langer SJ, Sloane EM, et al. Controlling pathological pain by adenovirally driven spinal production of the anti-inflammatory cytokine, interleukin-10. Eur J Neurosci. 2005;21(8):2136-2148.

75. Milligan ED, Sloane EM, Langer SJ, et al. Controlling neuropathic pain by adeno-associated virus driven production of the anti-inflammatory cytokine, interleukin-10. Mol Pain. 2005;1:9.

76. Goss JR, Gold MS, Glorioso JC. HSV vector-mediated modification of primary nociceptor afferents: an approach to inhibit chronic pain. Gene Ther. 2009;16(4):493-501.

77. Srinivasan R, Wolfe D, Goss J, et al. Protein kinase C epsilon contributes to basal and sensitizing responses of TRPV1 to capsaicin in rat dorsal root ganglion neurons. Eur J Neurosci. 2008;28(7):1241-1254.

78. Goss JR, Cascio M, Goins WF, et al. HSV delivery of a ligand-regulated endogenous ion channel gene to sensory neurons results in pain control following channel activation. Mol Ther. 2011;19(3):500-506.

79. Cummins TR, Sheets PL, Waxman SG. The roles of sodium channels in nociception: implications for mechanisms of pain. Pain. 2007;131(3): 243-257.

80. Cox JJ, Reimann F, Nicholas AK, et al. An SCN9A channelopathy causes congenital inability to experience pain. Nature. 2006;444(7121): 894-898. 
81. Waxman SG. Channel, neuronal and clinical function in sodium channelopathies: from genotype to phenotype. Nat Neurosci. 2007;10(4):405-409.

82. Chattopadhyay M, Zhou Z, Hao S, Mata M, Fink DJ. Reduction of voltage gated sodium channel protein in DRG by vector mediated miRNA reduces pain in rats with painful diabetic neuropathy. Mol Pain. 2012;8:17.

83. Yeomans DC, Levinson SR, Peters MC, et al. Decrease in inflammatory hyperalgesia by herpes vector-mediated knockdown of Nav1.7 sodium channels in primary afferents. Hum Gene Ther. 2005;16(2): 271-277.

84. Akopian AN, Sivilotti L, Wood JN. A tetrodotoxin-resistant voltagegated sodium channel expressed by sensory neurons. Nature. 1996;379(6562):257-262.
85. Goss JR, Fetterfolf C, Gains W, et al. Engineered zinc finger protein transcription factors as a potential therapy for neuropathic pain. Presented at the 12th World Congress on Pain, Glasgow, Scotland, August 17-22, 2008.

86. Goverdhana S, Puntel M, Xiong W, et al. Regulatable gene expression systems for gene therapy applications: progress and future challenges. Mol Ther. 2005;12(2):189-211.

87. Wu Z, Mata M, Fink DJ. Prolonged regulatable expression of EPO from an HSV vector using the LAP2 promoter element. Gene Ther. 2012;19(11):1107-1113.

88. Zou W, Huang C, Yang Y, Pan Y, Yan J, Guo Q. Microinjection of HSV-1 amplicon vector-mediated human proenkephalin into the periaqueductal grey attenuates neuropathic pain in rats. Int J Neurosci. 2012;122(4):189-194.

\section{Publish your work in this journal}

The Journal of Pain Research is an international, peer-reviewed, open access, online journal that welcomes laboratory and clinical findings in the fields of pain research and the prevention and management of pain. Original research, reviews, symposium reports, hypothesis formation and commentaries are all considered for publication.

\section{Dovepress}

The manuscript management system is completely online and includes a very quick and fair peer-review system, which is all easy to use. Visit http://www.dovepress.com/testimonials.php to read real quotes from published authors. 